Trevisan LV \& Coronel DA. (2020). Quality of services provided by the nucleus of transport of a federal higher education institution. Research, Society and Development, 9(7):1-27, e541974444.

\title{
Qualidade dos serviços prestados pelo núcleo de transporte de uma instituição federal de ensino superior
}

\section{Quality of services provided by the nucleus of transport of a federal higher education institution}

\section{Calidad de servicios proporcionados por el núcleo de transporte de una institución federal de educación superior}

Recebido: 12/05/2020 | Revisado: 16/05/2020 | Aceito: 16/05/2020 | Publicado: 26/05/2020

\section{Laís Viera Trevisan}

ORCID: https://orcid.org/0000-0003-3673-6573

Universidade Federal de Santa Maria, Brasil

E-mail: laisvtrevisan@gmail.com

Daniel Arruda Coronel

ORCID: https://orcid.org/0000-0003-0264-6502

Universidade Federal de Santa Maria, Brasil

E-mail:daniel.coronel@uol.com.br

\section{Resumo}

O presente estudo buscou, por meio da adaptação e aplicação de um instrumento de avaliação, realizar uma pesquisa com os usuários do setor de transporte de uma instituição federal de ensino superior e, por consequência, verificar em quais dimensões da qualidade e em quais aspectos o setor deve se aprimorar. Portanto, o objetivo geral do trabalho foi identificar a percepção dos usuários em relação à qualidade dos serviços prestados. Assim, este trabalho foi apresentado como um estudo de caso e classificou-se como uma pesquisa de natureza descritiva com uma abordagem metodológica quantitativa. Como instrumento de pesquisa, foi utilizado um questionário, baseado nas escalas SERVPERF e QUALBUS. Coletou-se um total de 512 questionários. Os principais resultados revelam que tanto os pontos positivos quanto os negativos da avaliação dos usuários referiram-se, especialmente, aos fatores "Confiabilidade e Segurança nas viagens" e "Empatia nas viagens". Também se analisaram as diferenças de avaliação segundo o perfil dos usuários, sendo que seis variáveis apresentaram diferenças de média: tipo de vínculo, tempo de instituição, cargo de chefia, tipo de utilização 
do transporte, nível de dificuldade de agendamento e transporte de outra instituição. Também foram feitas diversas proposições acerca dos fatores/categorias pesquisados, entre as quais destacam-se: implantar um sistema informatizado para o agendamento do transporte, investir na capacitação e profissionalização da secretaria e dos motoristas, melhorar as condições mecânicas dos veículos e realizar pesquisas de satisfação/avaliação das viagens.

Palavras-chave: Administração pública; Avaliação; Transporte.

\begin{abstract}
This study sought, through the adaptation and application of an evaluation instrument, to conduct a survey with users of the transport sector of a federal institution of higher education and, consequently, to verify in which dimensions of quality and in which aspects the sector should improve. Therefore, the general objective of the work was to identify the users' perception in relation to the quality of the services provided. Thus, this study was presented as a case study and was classified as a research of a descriptive nature with a quantitative methodological approach. As a research instrument, a questionnaire was used, based on the SERVPERF and QUALBUS scales. A total of 512 questionnaires were collected. The main results reveal that both the positive and negative points of the users' evaluation referred, especially, to the factors "Reliability and Safety in travel" and "Empathy in travel". Differences in assessment were also analyzed according to the profile of users, with six variables showing differences in mean: type of link, length of institution, management position, type of use of transportation, level of difficulty in scheduling and transportation from another institution. Several propositions were also made about the factors/categories surveyed, among which the following stand out: implementing a computerized system for scheduling transportation, investing in the training and professionalization of the secretariat and drivers, improving the mechanical conditions of vehicles and conducting research on travel satisfaction/assessment.
\end{abstract}

Keywords: Public administration; Evaluation; Transport.

\title{
Resumen
}

Este estudio buscó, a través de la adaptación y aplicación de un instrumento de evaluación, realizar una encuesta con usuarios del sector del transporte de una institución federal de educación superior y, en consecuencia, verificar en qué dimensiones de calidad y en qué aspectos el sector debería mejorar. Por lo tanto, el objetivo general del trabajo fue identificar la percepción de los usuarios en relación a la calidad de los servicios prestados. Por 
consiguiente, este trabajo se presentó como un estudio de caso y se clasificó como una investigación de naturaleza descriptiva con un enfoque metodológico cuantitativo. Como instrumento de investigación, se utilizó un cuestionario basado en las escalas SERVPERF y QUALBUS. Se recolectó un total de 512 cuestionarios. Los principales resultados revelan que tanto los puntos positivos como negativos de la evaluación de los usuarios se referían, especialmente, a los factores "Confiabilidad y seguridad en los viajes" y "Empatía en los viajes". Las diferencias en la evaluación también se analizaron de acuerdo con el perfil de los usuarios, con seis variables que muestran diferencias en la media: tipo de enlace, tiempo en la institución, posición de gestión, tipo de uso del transporte, nivel de dificultad en la programación y el transporte de otra institución. También se hicieron varias propuestas sobre los factores/categorías encuestados, entre los que se destacan los siguientes: implementar un sistema computarizado para programar el transporte, invertir en la capacitación y profesionalización de la secretaría y los conductores, mejorar las condiciones mecánicas de los vehículos y realizar investigaciones sobre satisfacción de viaje/evaluación.

Palabras clave: Administración pública; Evaluación; Transporte.

\section{Introdução}

Ao se analisar o contexto brasileiro, observa-se a importância de aprimorar a gestão das organizações públicas, as quais possuem um compromisso social e ético com a sociedade. Nesse sentido, as atividades realizadas devem estar pautadas e estruturadas nas necessidades e expectativas dos usuários e da sociedade em si. Para tanto, é imprescindível compreender como esses atores avaliam a qualidade dos serviços prestados pela administração pública.

Dentro desse cenário, insere-se a avaliação, a qual, para Ramos \& Schabbach (2012), é um instrumento importante para a melhoria da eficiência do gasto público, da qualidade da gestão, do aprimoramento do processo de tomada de decisão, permitindo aos formuladores e gestores de políticas públicas desenharem políticas mais consistentes.

Nessa lógica, alguns autores têm pesquisado o cenário de organizações públicas e buscado avaliar a qualidade dos serviços prestados por essas, a exemplo de pesquisas realizadas em instituições de ensino superior, Cunha et al. (2017); Almeida et al. (2018); Carvalho et al. (2018); Moreira Jr et al. (2015); Soares et al. (2019). Alguns exemplos de estudos realizados no setor de transporte público são os de Antunes \& Simões (2013), Antunes et al. (2017), Costa et al. (2017), Donato et al. (2017), Freitas \& dos Reis (2013), 
Lima et al. (2015), Lübeck et al. (2011) e Mattos et al. (2017). Entretanto, observa-se uma escassez no que tange ao setor de transporte dentro de organizações públicas.

Nesse sentido, nesta pesquisa, é abordado o setor de transporte de uma instituição de ensino superior brasileira. No que se refere ao seu propósito como organização, de acordo com Santos (2015), as universidades públicas federais têm papel importante para o desenvolvimento do país, interagindo com o poder público, o setor produtivo e a sociedade e estimulando a produção, criação e difusão cultural, filosófica, científica e artística.

Entre as 63 universidades públicas federais de ensino superior no Brasil, está a Universidade Federal de Santa Maria (UFSM), instituição escolhida como estudo de caso desta pesquisa. O Núcleo de Transporte está associado à Pró-Reitoria de Infraestrutura (Proinfra) e para atuar na sua área de competência, o setor tem de lidar com um intenso fluxo de documentos e de atendimento ao público, o que demanda planejamento, organização, padronização e qualificação de seu pessoal.

Considerando esse contexto, em diversos momentos os processos apresentam equívocos e demoras, o que acaba gerando insatisfação dos usuários dos serviços e, posteriormente, reclamações ao setor. Entretanto, em termos legais, o inciso I do artigo $6^{\circ}$ da Lei n. 8.987, de 13 de fevereiro de 1995, define o que é um "serviço adequado", ou seja, quais são os parâmetros mínimos de qualidade para a prestação de serviços públicos: "serviço adequado é o que satisfaz as condições de regularidade, continuidade, eficiência, segurança, atualidade, generalidade, cortesia na sua prestação e modicidade das tarifas" (Brasil, 1995).

Assim, uma vez que existe uma legislação que prevê a prestação de serviço adequado ao pleno atendimento dos usuários por parte das organizações públicas e um guia metodológico (Brasil, 2014) que dispõe sobre os padrões mínimos de desempenho institucional dessas atividades, é imprescindível conhecer os anseios e percepções dos usuários de instituições públicas e, especificamente neste caso, do setor de transporte da UFSM. A partir dessa constatação, também é essencial identificar melhorias e propor soluções, pois o entendimento dessas características pode contribuir para a prestação de serviços com um nível de qualidade que atenda às necessidades e expectativas dos usuários.

Ademais, considerando que, para o planejamento estratégico, a avaliação é elemento crítico e pode ser um suporte para a tomada de decisões, verificando se os resultados produzidos estão de acordo com a direção dos resultados esperados, dentro de um processo contínuo de avaliação-aprendizagem-avaliação, pergunta-se: qual é a percepção dos usuários do Núcleo de Transporte da Universidade Federal de Santa Maria em termos de qualidade dos serviços prestados? Portanto, o objetivo geral deste trabalho é: identificar a percepção dos 
usuários em relação à qualidade dos serviços prestados pelo Núcleo de Transporte da UFSM. E os objetivos específicos são: a) identificar o perfil dos usuários do Núcleo de Transporte da UFSM; b) verificar os pontos positivos e críticos da avaliação; c) analisar as diferenças de avaliação da qualidade do setor, segundo o perfil dos usuários; e d) propor melhorias à gestão do setor.

$\mathrm{O}$ presente trabalho está estruturado em quatro seções, além desta introdução. $\mathrm{Na}$ segunda seção, encontra-se o referencial teórico, na qual são expostos os temas: setor de serviços, qualidade, avaliação da qualidade e modelos de avaliação da qualidade. Na terceira seção, são descritos os procedimentos metodológicos da pesquisa. Na quarta, é realizada a análise dos resultados, a qual está dividida em: análise quantitativa e, plano de ações. Por fim, a quinta seção aborda as considerações finais.

\section{Referencial Teórico}

\subsection{Setor de serviços}

O setor de serviços corresponde ao setor terciário e abrange diversos ramos, como hotéis, transportadoras, restaurantes, seguradoras, entre outros, abrangendo inclusive as organizações públicas e sem fins lucrativos (Lovelock \& Wright, 2001).

Kotler \& Keller (2006, p. 397) afirmam que serviço "é qualquer ato ou desempenho, essencialmente intangível, que uma parte pode oferecer à outra e que não resulta na propriedade de nada". Para Fitzsimmons \& Fitzsimmons (2005, p. 30), um serviço "é uma experiência perecível, intangível, desenvolvida para um consumidor que desempenha o papel de coprodutor".

Em relação ao serviço público, de acordo com o guia metodológico "Carta de Serviços ao Cidadão" (Brasil, 2014), é uma atividade não privativa, na qual a ação do Estado tem um beneficiário final, seja ele um cidadão, seja uma empresa ou mesmo um órgão ou entidade pública.

Parasuraman, Zeithaml \& Berry (1988) destacam três pontos como características dos serviços, que devem ser reconhecidas para uma compreensão completa da qualidade do serviço: a) intangibilidade: a maioria dos serviços não pode ser contada nem medida; b) heterogeneidade: o desempenho dos serviços varia de produtor para produtor, de cliente para cliente e de dia para dia; e c) inseparabilidade: não se pode produzir ou estocar serviços como 
se faz com os bens, os serviços são criados e consumidos simultaneamente em uma interação entre o cliente e a pessoa de contato da empresa.

\subsection{Qualidade}

A empresa fornece qualidade sempre que seu produto ou serviço atende às expectativas do cliente ou as excede (Kotler \& Keller, 2006). Ainda, os autores afirmam que a qualidade é a totalidade dos atributos e características de um produto ou serviço que afetam sua capacidade de satisfazer necessidades declaradas ou implícitas.

No que tange às organizações públicas, Carvalho e Tonet (1994) afirmam que a expectativa da sociedade com relação aos serviços recebidos do setor público tem se modificado, pois a população pede mais e melhores serviços públicos e cobra melhor gestão dos recursos e do patrimônio público. Dessa forma, o sentimento de cidadania tem feito com que a sociedade abandone a posição passiva em relação às ações do governo e se organize para exigir maior eficiência/eficácia da administração pública.

Nesse contexto, desde 1990, o governo federal estimula o desenvolvimento de programas para a melhoria da qualidade na gestão dos órgãos públicos. Um marco importante nesse sentido foi a implementação do Programa de Qualidade na Administração Pública, no período em que Luiz Carlos Bresser Pereira esteve à frente do Ministério da Administração Federal e Reforma do Estado (1995-1998). Nessa época, foi concebido o Plano Diretor da Reforma do Aparelho do Estado. O principal instrumento do plano foi o Programa de Qualidade e Participação na Administração Pública, que se propôs a introduzir no setor público as mudanças de valores e comportamentos preconizados pela administração pública gerencial e, ainda, viabilizar a revisão dos processos internos da administração pública com vistas à sua maior eficiência e eficácia (Brasil, 1997).

Em 1999, o governo federal alterou o nome do programa para Programa de Qualidade do Setor Público, que passou a dar maior ênfase nas necessidades dos cidadãos como referencial de desempenho da administração pública, com foco em resultado. Em 2005, substituindo o Programa, o governo federal instituiu o Programa Nacional de Gestão Pública e Desburocratização (GESPÚBLICA), mantendo-se fiel à finalidade de contribuir para a melhoria da qualidade dos serviços públicos prestados aos cidadãos e para o aumento da competitividade do país mediante a melhoria contínua da gestão. Ainda, o grande objetivo do GESPÚBLICA seria sair do serviço à burocracia e colocar a gestão pública a serviço do resultado dirigido ao cidadão (Brasil, 2009). 
Entretanto, ressalta-se que houve a revogação do Programa GESPÚBLICA, a partir da publicação do Decreto n. 9.094, de 17 de julho de 2017. A revogação foi realizada a fim de sanar a sobreposição de programas e acompanhar os diversos esforços de melhoria da gestão pública que estão sendo realizados por meio da Plataforma de Cidadania Digital, instituída pelo Decreto n. 8.936, de 19 de dezembro de 2016, e com a criação do Conselho Nacional para a Desburocratização (Brasil, 2017).

\subsection{Avaliação da qualidade e modelos de avaliação da qualidade}

Para Bartnik \& Silva (2009), a avaliação é uma ferramenta de gestão e um exercício para execução de qualquer tarefa com qualidade e serve de base para a comparação entre a realidade de um objeto e seu estado desejável. além disso, a avaliação institucional deve ser um processo contínuo, que busque nortear as políticas institucionais, identificar distorções para corrigi-las e democratizar informações.

Ao longo das últimas décadas, diversos pesquisadores têm empreendido esforços para compreender a qualidade dos serviços prestados, por meio da identificação de fatores determinantes à qualidade e do desenvolvimento de técnicas de medição.

Miguel \& Salomi (2004) fizeram uma revisão de literatura sobre os principais modelos e conceitos referentes à mensuração da qualidade de serviços. Conforme os autores, um dos primeiros estudos para mensuração da qualidade em serviços foi desenvolvido por Grönroos (1984), denominado Perceived Service Quality (PSQ). Em seguida, em 1985, Parasuraman, Zeithaml \& Berry propuseram um modelo baseado em Oliver (1980), o qual também foi utilizado por Brown \& Swartz (1989). Na sequência, Parasuraman, Zeithaml \& Berry (1988) complementaram seu modelo com o instrumento denominado Service Quality (SERVQUAL), composto por 22 itens distribuídos em cinco dimensões da qualidade. Com base nesse estudo, outros autores apresentaram modelos que buscaram aperfeiçoá-lo, a exemplo de Bolton e Drew (1991), com o Modelo de avaliação de serviço e valor, Cronin e Taylor (1992), com o modelo Service Performance (SERVPERF) e Teas (1993), com o modelo Evaluated Performance (EP).

Existem diversos outros modelos e autores que tratam dos modelos de qualidade em serviços, no entanto, conforme pesquisas bibliométricas realizadas em bases de dados internacionais por Castro Jr et al. (2013) e Pereira et al. (2013), identificou-se que os estudos que mais se destacam na literatura em termos de utilização e citação são os de Parasuraman, 
Zeithaml \& Berry (1988), com a ferramenta SERVQUAL e de Cronin \& Taylor (1992), com o SERVPERF.

Em virtude de o modelo SERVPERF tratar-se de uma escala genérica, ou seja, que pode ser aplicada em vários tipos de serviços, alguns autores realizaram adaptações no modelo considerando as especificidades e características do serviço. No contexto dos serviços públicos de transporte, foram realizados diversos estudos por pesquisadores que tentaram propor modelos a fim de avaliar a qualidade desse tipo de serviço. Entretanto, embora existam diversos modelos que buscaram avaliar a qualidade dos serviços prestados por transportes públicos, Vila \& Gimeno-Martínez (2010) afirmam que a SERVPERF é a que mais tem recebido aceitação no âmbito de medição da qualidade dos serviços de transporte público.

Nesse sentido, o presente estudo ressalta a pesquisa realizada por Pérez et al. (2007), o qual adaptou o modelo SERVPERF para o setor de transporte, por meio de um trabalho aplicado no setor de transporte público da cidade de Almería, na Espanha. O estudo procurou examinar a relação entre a qualidade do serviço e as intenções de compra comportamental no setor de transporte público, confirmando essa ligação e contribuindo metodologicamente com uma escala de medição para a qualidade do serviço no setor de transporte público, denominando o modelo de QUALBUS. Essa escala já foi utilizada em alguns estudos, como o de Ojo et al. (2015), Vila \& Gimeno-Martínez (2010), de Grohmann et al. (2014) e de Bakti $\&$ Sumaedi (2015).

$\mathrm{Na}$ sequência, a próxima seção aborda os procedimentos metodológicos que conduziram esta pesquisa.

\section{Metodologia}

\subsection{Delineamento da pesquisa e descrição do estudo de caso}

Esta pesquisa é apresentada como um estudo de caso, de natureza descritiva com abordagem metodológica quantitativa como preconiza Pereira et al. (2018).

Entre as 63 universidades públicas federais de ensino superior existentes no Brasil está a Universidade Federal de Santa Maria (UFSM), criada no dia 14 de dezembro de 1960. Sua sede está localizada em Santa Maria, no centro do estado do Rio Grande do Sul. A UFSM, atualmente, conta com 11 unidades de ensino superior dentro de seu campus sede, além do Espaço Multidisciplinar da UFSM em Silveira Martins e dos outros três campi, localizados nos municípios de Cachoeira do Sul, Palmeira das Missões e Frederico Westphalen. 
Conforme dados obtidos no Portal da UFSM (UFSM, 2019), a universidade oferece 265 cursos, sendo 131 cursos de graduação e 105 cursos de pós-graduação. Assim, o corpo discente é constituído por 25.532 alunos, em todas as modalidades de ensino, e 4.746 servidores, sendo 2.027 docentes e 2.719 técnicos administrativos em educação (TAEs).

O Núcleo de Transporte está subordinado à Pro-Reitoria de Infraestrutura (Proinfra) e, de acordo com o inciso II do artigo 24 do Regimento Geral da UFSM, de 15 de abril de 2011, é responsável por "planejar, coordenar, executar e controlar os serviços de transporte oficial, os serviços de abastecimento, lavagem, lubrificação e manutenção de veículos, máquinas e equipamentos" (UFSM, 2011, p. 9).

Neste contexto, o Núcleo de Transporte tem como principal função auxiliar no deslocamento de servidores, docentes e discentes da UFSM, bem como de outras instituições a serviço da universidade, com o objetivo de desenvolver atividades acadêmicas e/ou administrativas, dentro do município de Santa Maria ou para outras cidades.

\subsection{População e amostra}

Tendo em vista que o setor de transporte da UFSM não possui registro de todos os indivíduos que já utilizaram os serviços do setor, considerou-se como população deste estudo a soma dos docentes (2.027), técnicos administrativos em educação (2.719) e professores/tutores Universidade Aberta do Brasil (UAB)/Ensino a Distância (EaD) (350) da UFSM, segundo dados disponíveis no portal da instituição (UFSM, 2019).

Assim, para o cálculo do tamanho da amostra, considerou-se um erro amostral de 5\%, com 95\% de confiança e uma população finita de 5.096 indivíduos. Dessa maneira, a amostra final a ser investigada é de, no mínimo, 358 indivíduos. Entretanto, a amostra coletada superou a mínima, ainda que tenha sido necessária a exclusão de 42 questionários, pois não estavam devidamente preenchidos. Assim, o total de respondentes deste estudo foi de 512 indivíduos.

\subsection{Técnicas de coleta e análise dos dados}

Este estudo iniciou-se com o levantamento de referencial bibliográfico de diversos autores acerca dos temas abordados no referencial teórico. Em um segundo momento, realizou-se uma pesquisa documental por meio de documentos e materiais disponibilizados 
pelo site da UFSM e pelo Núcleo de Transporte. Após, para a coleta dos dados quantitativos, foi empregado o método survey.

O questionário da pesquisa foi dividido em duas partes: perfil do respondente e avaliação do serviço. A primeira parte do questionário buscou identificar o perfil dos respondentes, constando perguntas sobre o sexo, estado civil, idade, renda familiar mensal, escolaridade, tipo de vínculo com a instituição, tempo de serviço na instituição, se possui cargo de chefia, centro de ensino ou unidade em que trabalha, frequência da utilização do transporte, se já utilizou o transporte de outra instituição pública, objetivos da utilização, se já teve problemas na prestação do serviço, se agenda e utiliza o transporte ou apenas utiliza, se possui dificuldade para agendar.

A segunda parte do questionário foi dividida de acordo com a utilização do usuário, ou seja, os indivíduos que agendam e utilizam o transporte responderam a duas avaliações, uma referente ao agendamento (atendimento da secretaria) e outra em relação à viagem (transporte em si e motoristas), enquanto os usuários que apenas utilizam o transporte responderam somente à segunda avaliação.

A avaliação do agendamento foi feita a partir da escala SERVPERF, desenvolvida por Cronin e Taylor (1992). Justifica-se a opção por esse modelo por ser de ampla utilização na literatura, como demonstrado na seção do referencial teórico. Assim, o questionário contou com 22 variáveis distribuídas em cinco dimensões da qualidade: tangibilidade, confiabilidade, presteza, segurança e empatia. Para cada uma das variáveis, os respondentes deveriam assinalar sua resposta em uma escala intervalar do tipo Likert, indicando seu grau de concordância em relação às variáveis, em uma escala de 5 pontos, sendo 1 para discordo totalmente e 5 para concordo totalmente. Ademais, foi acrescentada a opção "não estou apto a responder", caso o indivíduo não soubesse como responder à questão. Entretanto, foram realizadas pequenas adaptações na escala SERVPERF para a realidade do setor de transporte da UFSM.

Para a avaliação do transporte e dos motoristas, foi utilizada a escala QUALBUS, adaptada por Pérez et al. (2007) ao setor de transporte a partir do modelo SERVPERF. Essa escala possuiu 21 variáveis. A fim de adaptar a escala à realidade do setor, também foram realizadas algumas modificações nas variáveis. Além disso, no final dos dois instrumentos, foi adicionado um item solicitando aos respondentes que se posicionassem, numa escala de 0 a 10, quanto à sua satisfação em relação ao transporte da UFSM.

Entrou-se em contato com os usuários que o setor de transporte possuía registro de utilização do serviço, a fim de convidá-los a participar da pesquisa, e foram entregues 
questionários físicos ou encaminhados e-mails com o questionário on-line, com auxílio da ferramenta Google Drive. Outra forma de coleta utilizada foi o sistema de questionários do Centro de Processamento de Dados (CPD) da UFSM, o qual, com as devidas autorizações institucionais, encaminhou o questionário via sistema a todos os servidores ativos da UFSM.

Ressalta-se que antes de iniciar a aplicação dos questionários, foi realizado um préteste com dez servidores da UFSM, a fim de verificar modificações necessárias na redação e estrutura do instrumento. Além disso, a pesquisa foi aprovada pelo Comitê de Ética da UFSM.

Os dados foram tabulados no software Excel e, na sequência, foram exportados para o software SPSS (Statistical Package for the Social Sciences). Para atender aos objetivos "identificar o perfil dos usuários" e "verificar os pontos positivos e críticos da avaliação", foram utilizadas a estatística descritiva, distribuição de frequências, médias e desvio-padrão. Para atender ao objetivo "analisar as diferenças de avaliação da qualidade do setor, segundo o perfil dos usuários", foi realizado o Teste T. E, por fim, com o intuito de "propor melhorias à gestão do setor", foi elaborado um plano de ações contendo sugestões ao setor, a partir das avaliações dos usuários. A seção seguinte apresenta a análise dos resultados.

\section{Resultados e Discussões}

\subsection{Análise quantitativa}

\subsubsection{Perfil dos respondentes}

Esta pesquisa obteve um total de 512 respondentes, dos quais 227 são docentes, 240 são TAEs e 55 são professores/tutores $\mathrm{EaD/UAB}$, sendo que, destes últimos, sete também são docentes da UFSM e três também são TAEs; os outros 45 não são servidores da UFSM.

Constatou-se que a maior parte da amostra é do sexo feminino (52,54\%), a categoria mais representativa é casada (44,14\%), possui idade entre 46 e 60 anos (35,94\%), renda bruta familiar mensal acima de $\mathrm{R} \$ 12.001,00(29,30 \%)$ e doutorado completo (35,42\%). No que tange ao tipo de vínculo com a UFSM, a categoria mais representativa é composta por TAEs (46,88\%). Ademais, a classe com maior frequência possui de 5 a 10 anos de vínculo com a UFSM $(31,25 \%)$ e não possui cargo de chefia $(64,06 \%)$.

$\mathrm{O}$ centro com maior número de respondentes foi o Centro de Ciências Sociais e Humanas (9,96\%), seguido pelo Centro de Educação (9,57\%) e Centro de Ciências Rurais $(8,98 \%)$. A categoria mais representativa da amostra utiliza o transporte com a frequência de 
4 meses ou mais (44,34\%), e ainda não utilizou o transporte de outra instituição pública $(58,20 \%)$.

Sobre os principais objetivos da utilização do transporte, a opção mais marcada foi "visita de estudo" (45,31\%). A respeito da ocorrência de problemas na prestação de serviço, $43,16 \%$ dos respondentes nunca tiveram problemas, entretanto o restante marcou diversas opções, sendo que a classe de maior frequência relaciona-se a problemas com falta de prudência na direção $(20,51 \%)$, seguida por agendamento do transporte $(19,92 \%)$, descumprimento de horários $(18,95 \%)$, comportamento inadequado do motorista $(15,63 \%)$ e outros.

Referente à utilização do setor, a maior parte da amostra utiliza o transporte e realiza agendamentos $(54,49 \%)$, enquanto o restante apenas utiliza o transporte, mas não é responsável pelo agendamento. A maior parte dos respondentes possui pouca dificuldade para agendar (39,21\%), ainda que a resposta "média dificuldade" tenha sido expressiva $(33,09 \%)$.

\subsubsection{Avaliação dos usuários}

Na sequência da análise descritiva, identificaram-se os pontos positivos e críticos da avaliação dos usuários. Observou-se que na avaliação da qualidade do agendamento, as maiores médias foram para as variáveis: "Os funcionários do setor são educados" (média de 4,18), da dimensão Segurança, e "Os funcionários do setor possuem aparência boa e profissional" $(4,11)$, da dimensão Tangibilidade. Portanto, recomenda-se manter tais condutas no setor.

No entanto, as menores médias foram encontradas nas variáveis: "O serviço de agendamento do setor de transporte e os recursos utilizados para tal (formas de comunicação com o usuário) são modernos" (3,06), da dimensão Tangibilidade, e "Os funcionários do setor lhe dão atenção personalizada" $(3,21)$, da dimensão Empatia. Esses resultados sinalizam a necessidade de a gestão rever a forma e os recursos para o agendamento de transporte, buscando uma modernização e adequação às necessidades dos usuários, bem como melhorias em relação à dimensão Empatia, buscando o aprimoramento profissional do pessoal da secretaria.

Na sequência, foi realizada a avaliação da qualidade referente às viagens/motoristas. Assim, verificou-se que as variáveis mais bem avaliadas pelos usuários foram: "Os motoristas possuem aparência boa e profissional" $(4,28)$, da dimensão Tangibilidade, "As informações fornecidas pelos motoristas são cumpridas (horários, itinerário etc.)” (4,23), da dimensão 
Confiabilidade, "Os motoristas demonstram boa vontade (prontidão) em atender às solicitações dos usuários" (4,23), da dimensão Presteza e "Os itinerários das viagens são convenientes aos usuários" $(4,23)$, da dimensão Empatia.

Contudo, as variáveis que apresentaram menores médias foram: "O setor de transporte da UFSM possui veículos em boas condições" $(3,66)$, da dimensão Tangibilidade, "Consigo realizar as viagens na data/horário que gostaria (o agendamento é realizado para a data/horário desejado)" (3,89) e "Os motoristas oferecem atenção individual aos passageiros" $(3,89)$, ambas da dimensão Empatia. Esses resultados indicam a relevância de melhorias no que tange às condições dos veículos do setor, assim como é válido que a gestão analise a questão do agendamento para a data/horário desejado em conjunto com a avaliação do agendamento, verificando a possibilidade de aperfeiçoar esse tema e buscando atender da melhor forma às expectativas dos usuários, sem olvidar, ainda, a grande demanda que o setor possui. E, ainda, a necessidade de aprimorar a atenção dos motoristas para com os passageiros.

Comparando os resultados da avaliação da qualidade do agendamento com as viagens/motoristas, verifica-se que, de forma geral, as médias da segunda avaliação foram superiores às da primeira, isso para todas as dimensões analisadas. Portanto, é possível constatar que os respondentes avaliam de forma mais positiva os serviços das viagens e motoristas do que os serviços prestados pela secretaria. No entanto, vale salientar que, para todas as dimensões, foram constatadas boas condutas e outras em que são necessários aprimoramentos.

No final das duas avaliações da qualidade, os respondentes foram questionados, em uma escala de 0 a 10 (sendo 0 nada satisfeito e 10 totalmente satisfeito), a respeito de sua satisfação com o setor de transporte, referente ao agendamento e às viagens/motoristas. Verifica-se que, para o serviço de agendamento do transporte, os respondentes apresentaram média de satisfação de 7,38.

Assim, observa-se que, embora a maior parte dos respondentes tenha se mostrado satisfeita com os serviços de agendamento do setor, existe uma porcentagem expressiva de usuários insatisfeitos e muito insatisfeitos $(18,27 \%$ da amostra), com notas inferiores a 5. Portanto, é importante que a gestão do setor reflexione acerca dos aspectos menos bem avaliados pelos respondentes, os quais foram descritos na análise das médias das avaliações da qualidade, e busque soluções que visem aperfeiçoar a qualidade dos serviços prestados, bem como melhorar a satisfação dos usuários.

No que se refere à satisfação dos respondentes com as viagens/motoristas, esta apresentou média de 7,94. Isso mostra uma satisfação maior com esse quesito do que com o 
serviço de agendamento, entretanto também se visualiza que existem usuários descontentes com o serviço e, por isso, sugere-se que a gestão repense suas práticas, considerando os aspectos menos bem avaliados pelos respondentes.

\subsubsection{Análise fatorial}

Com o objetivo de agrupar as variáveis em um conjunto menor de dimensões ou fatores, é realizada a análise fatorial dos modelos de avaliação da qualidade. Para verificar quais variáveis fazem parte de cada fator, é realizado o Método de Rotação Varimax com normalização de Kaiser completo, bem como o teste de confiabilidade Alpha de Cronbach. Conforme Hair et al. (2009), a confiabilidade indica o grau de consistência interna entre os múltiplos indicadores de um fator e em análise exploratória deve possuir um valor superior a 0,6 .

A partir deste teste, foram gerados três fatores: o primeiro foi "Confiabilidade e Segurança no agendamento", o qual, composto por 11 variáveis, busca avaliar, principalmente, se o setor presta serviço de agendamento no tempo prometido e de forma confiável e precisa, bem como verifica a habilidade dos funcionários em transmitir confiança e segurança aos usuários. O segundo fator gerado foi "Empatia no agendamento", composto por seis variáveis, busca avaliar, de forma mais específica, os funcionários da secretaria, verificando se são capazes de compreender as necessidades dos usuários. O último fator gerado foi "Tangibilidade no agendamento", composto por três variáveis, possui o objetivo de identificar como os usuários avaliam o processo de agendamento. Na sequência, a Tabela 1 expõe as médias dos fatores gerados para a avaliação do agendamento.

Tabela 1 - Médias dos fatores Confiabilidade e Segurança no agendamento, Empatia no agendamento e Tangibilidade no agendamento.

\begin{tabular}{lc}
\hline \multicolumn{1}{c}{$\begin{array}{c}\text { Aspectos referentes a avaliação da qualidade do } \\
\text { agendamento }\end{array}$} & Média \\
\hline Confiabilidade e Segurança no agendamento & 3,80 \\
\hline Empatia no agendamento & 3,56 \\
\hline Tangibilidade no agendamento & 3,36 \\
\hline
\end{tabular}

Fonte: dados da pesquisa.

Conforme a Tabela 1, o fator mais bem avaliado pelos respondentes foi "Confiabilidade e Segurança no agendamento", com média de 3,80. O resultado da média 
próximo ao valor 4 indica uma avaliação mediana a boa, entretanto, é possível realizar melhorias, para que os usuários possuam maior confiança e segurança no serviço de agendamento.

À vista disso, a instituição pode empreender esforços em: prestar o serviço no tempo prometido, quando prometer algo em determinado tempo, realmente fazê-lo, informar exatamente quando os serviços serão executados, quando os usuários tiverem algum problema, ser solidário e deixá-los seguros, fornecer atendimento/informações imediatas, considerando a devida demanda do setor, oferecer segurança aos usuários no processo de agendamento, capacitar os funcionários da secretaria para que executem bem seu trabalho e para que mantenham os registros e informações sobre os agendamentos organizados e precisos.

O segundo fator que apresentou maior média foi "Empatia no agendamento" (média de 3,56). Tal resultado denota certa neutralidade dos respondentes a esse tema. Por isso, a fim de melhorar a qualidade do serviço, é válido que a gestão do setor aprimore os cuidados e a atenção fornecida pelos funcionários da secretaria por meio de ações como: entender as necessidades e interesses dos usuários e tê-los como objetivos, oferecer atenção personalizada e individualizada, prezar pela educação, cordialidade e disposição em auxiliar os usuários.

$\mathrm{O}$ fator com menor média e, portanto, menos bem avaliado pelos usuários, foi "Tangibilidade no agendamento" $(3,36)$. Verifica-se que a média está próxima ao valor 3 , assinalando indiferença dos usuários em relação a esse fator. Assim, é importante que o processo de agendamento, em termos de recursos físicos e formas de comunicação com o usuário, seja repensado e modernizado.

Em relação a análise fatorial realizada para a avaliação da qualidade das viagens/motoristas (Tabela 2), o primeiro fator foi denominado "Confiabilidade e Segurança nas viagens", constituído por 12 variáveis que tem como principal objetivo verificar o comportamento dos motoristas com os passageiros, identificando aspectos como: cordialidade, transmissão de confiança e segurança, boa vontade na prestação do serviço, aparência profissional, conhecimento para responder às perguntas, entre outros.

O segundo fator gerado foi "Empatia nas viagens", composto por cinco variáveis, busca avaliar a conveniência da prestação do serviço das viagens/motoristas, investigando questões como: agendamento de data e horário das viagens de acordo com as necessidades dos usuários, itinerários das viagens conforme seus interesses, pontualidade dos motoristas, etc. 
Por fim, o último fator gerado foi "Avaliação dos veículos", constituído por quatro variáveis, relaciona-se à aparência das instalações, equipamentos, pessoal e material de comunicação. Portanto, tem como principal intuito avaliar as condições dos veículos do setor e aspectos como limpeza, conforto e conformidade entre o veículo e o tipo de serviço solicitado.

Na sequência, a Tabela 2 apresenta as médias dos fatores gerados para a avaliação das viagens/motoristas.

Tabela 2 - Médias dos fatores Confiabilidade e Segurança nas viagens, Empatia nas viagens e Avaliação dos veículos.

\begin{tabular}{lc}
\hline $\begin{array}{c}\text { Aspectos referentes à avaliação da qualidade das } \\
\text { viagens/motoristas }\end{array}$ & Média \\
\hline Confiabilidade e Segurança nas viagens & 4,06 \\
\hline Empatia nas viagens & 4,10 \\
\hline Avaliação dos veículos & 3,96 \\
\hline
\end{tabular}

Fonte: dados da pesquisa.

Conforme a Tabela 2, de modo geral, os novos fatores gerados obtiveram boas médias, sendo que o fator mais bem avaliado foi "Empatia nas viagens" (média de 4,10). O resultado dessa avaliação implica afirmar que os usuários do transporte da UFSM, em média, percebem que a qualidade do serviço das viagens/motoristas no que se refere a aspectos de conveniência é boa. Portanto, é importante que tais condutas se mantenham no setor.

O segundo fator com maior média foi "Confiabilidade e Segurança nas viagens" $(4,06)$. Nesse sentido, considera-se válido que os motoristas mantenham suas boas atitudes com os passageiros e continuem transmitindo confiança e segurança nas viagens. Todavia, é possível que sejam realizadas melhorias, a fim de atender ainda mais às expectativas dos usuários.

Já o fator denominado "Avaliação dos veículos" foi o que apresentou menor média $(3,96)$. Embora o resultado tenha sido próximo ao valor 4 e, portanto, a avaliação da qualidade possa ser considerada boa, é válido que a instituição empreenda esforços em aprimorar os veículos do setor, cuidando a sua manutenção, limpeza, conforto e demais aspectos tangíveis.

Comparando as médias dos novos fatores gerados para a avaliação do agendamento com os da avaliação das viagens/motoristas, observa-se que, para todos os fatores, as médias da segunda avaliação foram superiores às da primeira. Isso demonstra que os usuários do setor de transporte da UFSM avaliaram a qualidade dos serviços prestados pelos motoristas e 
Research, Society and Development, v. 9, n. 7, e541974444, 2020

(CC BY 4.0) | ISSN 2525-3409 | DOI: http://dx.doi.org/10.33448/rsd-v9i7.4444

o que tange à viagem em si como superior à qualidade dos serviços de agendamento/secretaria. Nessa lógica, recomenda-se à gestão que priorize a melhoria dos serviços menos bem avaliados, ou seja, os serviços prestados pela secretaria do setor de transporte.

\subsubsection{Teste T de Student}

Com o intuito de verificar se existem diferenças de médias nos fatores gerados no modelo, segundo as variáveis de perfil dos respondentes, foi realizado o Teste T de Student. Nesse sentido, as variáveis que apresentaram diferenças de médias foram: tipo de vínculo com a UFSM, tempo de instituição, cargo de chefia, tipo de utilização, nível de dificuldade de agendamento e transporte de outra instituição.

Conforme a Tabela 3 apresenta, para a variável "tipo de vínculo com a UFSM", observou-se diferenças de médias nos fatores "Empatia no agendamento" e "Avaliação dos veículos". Nos dois fatores, a média para os servidores TAEs foi superior à dos docentes. Apesar de apenas esses fatores obterem diferenças significativas de média, em todos os outros as avaliações dos docentes foram inferiores às dos TAEs.

Tabela 3 - Teste T de Student para a variável "tipo de vínculo com a UFSM".

\begin{tabular}{cccccc}
\hline \multirow{2}{*}{ Escala } & Fatores & \multicolumn{2}{c}{ Média } & \multirow{2}{*}{ T } & \multirow{2}{*}{ Sig. } \\
\cline { 2 - 5 } & \multirow{3}{*}{ Agendamento } & Docente & TAE & & \\
& $\begin{array}{c}\text { Confiabilidade e Segurança no } \\
\text { agendamento }\end{array}$ & 3,676 & 3,859 & $-1,141$ & 0,256 \\
\cline { 2 - 6 } & Empatia no agendamento & 3,395 & 3,711 & $-2,159$ & 0,032 \\
\cline { 2 - 6 } & Tangibilidade no agendamento & 3,293 & 3,447 & $-1,067$ & 0,287 \\
\hline \multirow{3}{*}{$\begin{array}{c}\text { Viagens/ } \\
\text { Motoristas }\end{array}$} & $\begin{array}{c}\text { Confiabilidade e Segurança nas } \\
\text { viagens }\end{array}$ & 4,017 & 4,134 & $-1,335$ & 0,183 \\
\cline { 2 - 6 } & Empatia nas viagens & 4,058 & 4,158 & $-1,194$ & 0,233 \\
\cline { 2 - 5 } & Avaliação dos veículos & 3,909 & 4,077 & $-1,965$ & 0,050 \\
\hline
\end{tabular}

Fonte: dados da pesquisa.

Conforme a Tabela 4, para a variável "tempo de instituição", observou-se que a média dos respondentes que possuem mais de 5 anos de vínculo com a instituição foi significativamente superior no fator "Avaliação dos veículos". Essa constatação pode dever-se ao fato de que os servidores com maior tempo de vínculo com a instituição já podem estar "acostumados" com os veículos que a universidade possui, em função de já terem viajado mais vezes, conhecerem os possíveis problemas e, portanto, serem menos críticos em sua 
avaliação. No entanto, é válido que a UFSM busque melhorias na manutenção e conservação dos veículos, tendo em vista que podem colocar em risco a vida dos servidores nas viagens.

Tabela 4 - Teste T de Student para a variável "tempo de vínculo com a UFSM".

\begin{tabular}{|c|c|c|c|c|c|}
\hline \multirow[b]{2}{*}{ Escala } & \multirow[b]{2}{*}{ Fatores } & \multicolumn{2}{|c|}{ Média } & \multirow[b]{2}{*}{$\mathbf{T}$} & \multirow[b]{2}{*}{ Sig. } \\
\hline & & Até 5 anos & $\begin{array}{c}\text { Mais } \\
\text { de } 5 \\
\text { anos }\end{array}$ & & \\
\hline \multirow{3}{*}{ Agendamento } & $\begin{array}{l}\text { Confiabilidade e Segurança no } \\
\text { agendamento }\end{array}$ & 3,842 & 3,781 & 0,476 & 0,635 \\
\hline & Empatia no agendamento & 3,555 & 3,564 & $-0,069$ & 0,945 \\
\hline & Tangibilidade no agendamento & 3,257 & 3,429 & $-1,282$ & 0,201 \\
\hline \multirow{3}{*}{$\begin{array}{c}\text { Viagens/ } \\
\text { Motoristas }\end{array}$} & $\begin{array}{c}\text { Confiabilidade e Segurança nas } \\
\text { viagens }\end{array}$ & 4,116 & 4,023 & 1,106 & 0,269 \\
\hline & Empatia nas viagens & 4,006 & 4,161 & $-1,909$ & 0,057 \\
\hline & Avaliação dos veículos & 3,843 & 4,034 & $-2,304$ & 0,022 \\
\hline
\end{tabular}

Fonte: dados da pesquisa.

De acordo com a Tabela 5, para a variável "cargo de chefia", observou-se que os servidores que não possuem cargo de chefia avaliaram a qualidade do serviço com maior média que aqueles que possuem cargo no fator "Confiabilidade e Segurança no agendamento". Considerando que tal fator trata de questões como prestação do serviço no tempo prometido, informação da execução do serviço, solidariedade e segurança na ocorrência de problemas, conhecimento para execução do trabalho, uma justificativa para tal resultado pode ser que aqueles servidores com cargo de chefia estão mais habilitados, a princípio, para resolução de conflitos, transmissão de confiabilidade e segurança à equipe etc. Assim, devido à sua capacitação, também exigem que o mesmo seja feito pelos outros.

Tabela 5 - Teste T de Student para a variável "possui cargo de chefia".

\begin{tabular}{|c|c|c|c|c|c|}
\hline \multirow[b]{2}{*}{ Escala } & \multirow[b]{2}{*}{ Fatores } & \multicolumn{2}{|c|}{ Média } & \multirow[b]{2}{*}{$\mathbf{T}$} & \multirow[b]{2}{*}{ Sig. } \\
\hline & & $\begin{array}{c}\text { Não } \\
\text { possui }\end{array}$ & Possui & & \\
\hline \multirow{3}{*}{ Agendamento } & $\begin{array}{c}\text { Confiabilidade e Segurança } \\
\text { no agendamento }\end{array}$ & 3,907 & 3,630 & 2,053 & 0,042 \\
\hline & Empatia no agendamento & 3,617 & 3,468 & 1,144 & 0,254 \\
\hline & $\begin{array}{l}\text { Tangibilidade no } \\
\text { agendamento }\end{array}$ & 3,422 & 3,275 & 1,151 & 0,251 \\
\hline \multirow{3}{*}{$\begin{array}{c}\text { Viagens/ } \\
\text { Motoristas }\end{array}$} & $\begin{array}{c}\text { Confiabilidade e Segurança } \\
\text { nas viagens }\end{array}$ & 4,104 & 3,963 & 1,625 & 0,105 \\
\hline & Empatia nas viagens & 4,117 & 4,081 & 0,435 & 0,664 \\
\hline & Avaliação dos veículos & 3,956 & 3,980 & $-0,282$ & 0,778 \\
\hline
\end{tabular}

Fonte: dados da pesquisa. 
Conforme a Tabela 6, para a variável "tipo de utilização do transporte", verificou-se que em todos os fatores existem diferenças de médias entre os respondentes que utilizam o transporte e realizam agendamentos e aqueles que utilizam o transporte, mas não são responsáveis pelo agendamento. Constata-se que o primeiro grupo avaliou de forma mais crítica os fatores do que o segundo grupo.

Tais resultados podem dever-se ao fato de que as pessoas que utilizam o transporte e realizam agendamentos conhecem o processo como um todo, ou seja, possuem uma visão sistêmica dos serviços do setor. Baseado nisso e considerando que, em geral, as médias de avaliação do serviço de agendamento foram inferiores às da avaliação das viagens/motoristas, tal situação pode ter influenciado os usuários que utilizam o transporte e também agendam no que diz respeito à segunda avaliação, implicando piores avaliações.

Desse modo, é possível que aperfeiçoamentos efetuados no processo de agendamento façam com que a percepção dos usuários acerca da qualidade dos serviços dos motoristas e viagens também seja alterada.

Tabela 6 - Teste T de Student para a variável "tipo de utilização do transporte".

\begin{tabular}{cccccc}
\hline \multirow{2}{*}{ Escala } & Fatores & \multicolumn{2}{c}{ Média } & & \\
\cline { 2 - 5 } & $\begin{array}{c}\text { Utiliza e } \\
\text { agenda }\end{array}$ & $\begin{array}{c}\text { Apenas } \\
\text { utiliza }\end{array}$ & T & Sig. \\
\hline \multirow{3}{*}{ Agendamento } & $\begin{array}{c}\text { Confiabilidade e Segurança } \\
\text { no agendamento }\end{array}$ & 3,916 & 4,216 & $-3,730$ & 0,000 \\
\cline { 2 - 6 } & Empatia no agendamento & 4,000 & 4,235 & $-2,998$ & 0,003 \\
\cline { 2 - 6 } & $\begin{array}{c}\text { Tangibilidade no } \\
\text { agendamento }\end{array}$ & 3,861 & 4,088 & $-2,826$ & 0,005 \\
\hline \multirow{2}{*}{$\begin{array}{c}\text { Viagens/ } \\
\text { Motoristas }\end{array}$} & $\begin{array}{c}\text { Confiabilidade e Segurança } \\
\text { nas viagens }\end{array}$ & 3,916 & 4,216 & $-3,730$ & 0,000 \\
\cline { 2 - 6 } & Empatia nas viagens & 4,000 & 4,235 & $-2,998$ & 0,003 \\
\cline { 2 - 6 } & Avaliação dos veículos & 3,861 & 4,088 & $-2,826$ & 0,005 \\
\hline
\end{tabular}

Fonte: dados da pesquisa.

Segundo a Tabela 7, para a variável "nível de dificuldade de agendamento", houve uma diferença de média significativa no fator "Tangibilidade no agendamento", indicando que os respondentes que possuem pouca dificuldade para agendar avaliaram melhor o serviço de agendamento do transporte da UFSM do que aqueles que possuem média ou alta dificuldade. 
Nessa lógica, os usuários que possuem dificuldade para realizar agendamentos entendem que os recursos e meios de comunicação utilizados para tal poderiam ser aperfeiçoados.

Tabela 7 - Teste T de Student para a variável "nível de dificuldade de agendamento".

\begin{tabular}{ccccccc}
\hline \multirow{2}{*}{ Escala } & Fatores & $\begin{array}{c}\text { Pouca } \\
\text { dificuldade }\end{array}$ & $\begin{array}{c}\text { Média/alta } \\
\text { dificuldade }\end{array}$ & T & Sig. \\
\hline \multirow{2}{*}{ Agendamento } & $\begin{array}{c}\text { Confiabilidade } \\
\text { Segurança no } \\
\text { agendamento }\end{array}$ & 4,306 & 4,087 & 1,437 & 0,154 \\
\cline { 2 - 6 } & $\begin{array}{c}\text { Empatia no } \\
\text { agendamento }\end{array}$ & 4,035 & 3,913 & 0,784 & 0,434 \\
\cline { 2 - 6 } & $\begin{array}{c}\text { Tangibilidade no } \\
\text { agendamento }\end{array}$ & 4,049 & 3,665 & 2,385 & 0,018 \\
\hline
\end{tabular}

Fonte: dados da pesquisa.

De acordo com a Tabela 8, para a variável "transporte de outra instituição", verificouse diferenças de médias em todos os fatores; os usuários que já utilizaram transporte de outra instituição avaliaram pior a prestação do serviço do que aqueles que nunca utilizaram.

Esses resultados podem ser justificados considerando-se que aqueles usuários que já tiveram experiências de transporte em outras instituições públicas podem realizar comparações com o transporte da UFSM e, talvez, perceber que a qualidade do serviço é inferior à de outras organizações. Dessa forma, foram mais críticos ao responderem ao instrumento de avaliação desta pesquisa do que aqueles usuários que só utilizaram o transporte da UFSM e, portanto, não possuem vivências a comparar. Nesse sentido, ressaltase a necessidade de a gestão aprimorar suas práticas e investigar aquelas realizadas pelo setor de transporte de outras instituições públicas, buscando espelhar-se em boas condutas. 
Research, Society and Development, v. 9, n. 7, e541974444, 2020

(CC BY 4.0) | ISSN 2525-3409 | DOI: http://dx.doi.org/10.33448/rsd-v9i7.4444

Tabela 8 - Teste T de Student para a variável "transporte de outra instituição".

\begin{tabular}{|c|c|c|c|c|c|}
\hline \multirow[b]{2}{*}{ Escala } & \multirow[b]{2}{*}{ Fatores } & \multicolumn{2}{|c|}{ Média } & \multirow[b]{2}{*}{$\mathbf{T}$} & \multirow[b]{2}{*}{ Sig. } \\
\hline & & $\begin{array}{c}\text { Nunca } \\
\text { utilizaram }\end{array}$ & Já utilizaram & & \\
\hline \multirow{3}{*}{ Agendamento } & $\begin{array}{c}\text { Confiabilidade e Segurança no } \\
\text { agendamento }\end{array}$ & 3,866 & 3,188 & 3,398 & 0,001 \\
\hline & Empatia no agendamento & 3,613 & 2,849 & 3,665 & 0,000 \\
\hline & Tangibilidade no agendamento & 3,445 & 2,474 & 4,313 & 0,000 \\
\hline \multirow{3}{*}{$\begin{array}{c}\text { Viagens/ } \\
\text { Motoristas }\end{array}$} & $\begin{array}{c}\text { Confiabilidade e Segurança nas } \\
\text { viagens }\end{array}$ & 4,058 & 3,385 & 4,366 & 0,000 \\
\hline & Empatia nas viagens & 4,120 & 3,336 & 5,533 & 0,000 \\
\hline & Avaliação dos veículos & 3,966 & 3,198 & 5,201 & 0,000 \\
\hline
\end{tabular}

Fonte: dados da pesquisa.

Na sequência, é apresentado o plano de ações.

\subsection{Plano de ações}

Diante deste estudo, foi elaborado um plano de ações para o setor de transporte da UFSM, dando ênfase às sugestões e como realiza-las, conforme o Quadro 1 apresenta. 
Quadro 1 - Plano de ações.

\begin{tabular}{|c|c|}
\hline O QUÊ & COMO \\
\hline \multicolumn{2}{|c|}{ Confiabilidade e Segurança no agendamento } \\
\hline \multirow{2}{*}{ Diminuição de falhas de agendamento } & $\begin{array}{l}\text { Destinar os motoristas para a viagem com antecedência, para que } \\
\text { façam contato prévio com os passageiros. }\end{array}$ \\
\hline & $\begin{array}{l}\text { Encaminhar e-mails confirmativos automáticos sobre a viagem } \\
\text { (através de sistema informatizado). }\end{array}$ \\
\hline \multirow{2}{*}{$\begin{array}{l}\text { Esclarecimento de dúvidas dos } \\
\text { usuários }\end{array}$} & $\begin{array}{l}\text { Elaborar manual, a exemplo do elaborado pela Universidade } \\
\text { Federal do Pampa (Unipampa). }\end{array}$ \\
\hline & Realizar reuniões com as unidades administrativas. \\
\hline Organização dos registros do setor & Implantar um sistema informatizado de agendamento. \\
\hline \multicolumn{2}{|r|}{ Empatia no agendamento } \\
\hline $\begin{array}{l}\text { Melhoria na comunicação com as } \\
\text { coordenações EaD/UAB }\end{array}$ & $\begin{array}{l}\text { Realizar reuniões e contatos frequentes com as coordenações } \\
\mathrm{EaD} / \mathrm{UAB} \text {. }\end{array}$ \\
\hline Melhoria no atendimento & Oferecer cursos. \\
\hline \multicolumn{2}{|r|}{ Tangibilidade no agendamento } \\
\hline Melhoria no recurso de agendamento & $\begin{array}{l}\text { Implantar um sistema informatizado integrado ao Sistema de } \\
\text { Informações para o Ensino (SIE) da UFSM. }\end{array}$ \\
\hline Otimização de veículos & $\begin{array}{l}\text { Sempre que possível, agrupar os passageiros em um mesmo } \\
\text { veículo. }\end{array}$ \\
\hline Transparência das viagens & $\begin{array}{l}\text { Disponibilizar informações e custos das viagens no portal da } \\
\text { instituição, a exemplo do portal da Unipampa. }\end{array}$ \\
\hline \multicolumn{2}{|c|}{ Confiabilidade e Segurança nas viagens } \\
\hline \multirow{2}{*}{ Melhoria no serviço dos motoristas } & Oferecer cursos. \\
\hline & \multirow{2}{*}{ Empatia nas viagens } \\
\hline \multirow{4}{*}{$\begin{array}{l}\text { Maior disponibilidade de } \\
\text { motoristas/veículos }\end{array}$} & \\
\hline & $\begin{array}{l}\text { Estudo para verificar a disponibilidade de recursos para a } \\
\text { contratação. }\end{array}$ \\
\hline & $\begin{array}{l}\text { Verificar a possibilidade de motoristas fixos em unidades } \\
\text { específicas que possuem maior demanda. }\end{array}$ \\
\hline & $\begin{array}{l}\text { Buscar doações junto à Receita Federal de veículos apreendidos em } \\
\text { boas condições de utilização. }\end{array}$ \\
\hline Pontualidade do serviço & Cursos e reuniões frequentes com os motoristas. \\
\hline \multicolumn{2}{|r|}{ Avaliação dos veículos } \\
\hline Controle de excessos de velocidade & Utilizar GPS nos veículos e controlar a velocidade. \\
\hline $\begin{array}{l}\text { Diminuição de problemas mecânicos } \\
\text { nos veículos }\end{array}$ & $\begin{array}{l}\text { Implantar um checklist de verificação das condições dos veículos na } \\
\text { saída e chegada das viagens. }\end{array}$ \\
\hline $\begin{array}{l}\text { Frota acessível para portadores de } \\
\text { necessidades especiais }\end{array}$ & Aquisição de ao menos um veículo para atender a demanda. \\
\hline \multicolumn{2}{|r|}{ Outras Sugestões } \\
\hline Avaliação dos usuários & Pesquisas de satisfação/avaliação. \\
\hline
\end{tabular}

Fonte: dados da pesquisa.

É válido ressaltar que as sugestões aqui propostas não esgotam as possibilidades de melhorias no setor, pois são apenas algumas ideias que emergiram a partir dos resultados da pesquisa. É recomendável que a gestão do setor analise esse estudo em conjunto com as chefias superiores e busque verificar a viabilidade da sua implementação, de acordo com os recursos humanos, materiais e financeiros da instituição, prezando pela satisfação dos usuários. Isso porque, apesar de o setor não ser um fim em si mesmo - a educação sim o é -, ele é um importante meio para que essa seja desenvolvida, transportando servidores para realizar desde tarefas administrativas até visitas acadêmicas, aulas $\mathrm{EaD}$ etc. 


\section{Considerações Finais}

O presente estudo buscou realizar uma avaliação da qualidade dos serviços prestados pelo setor de transporte de uma instituição federal de ensino superior. Para tanto, buscou identificar o perfil dos usuários, verificar os pontos positivos e críticos da avaliação, analisar as diferenças de avaliação segundo o perfil dos usuários e propor melhorias à gestão.

Os principais resultados revelaram que tanto os positivos quanto os negativos referiramse especialmente aos fatores "Confiabilidade e Segurança nas viagens" e "Empatia nas viagens". Em relação às diferenças de avaliação segundo o perfil dos usuários, seis variáveis apresentaram diferenças de média. Também foram feitas diversas proposições acerca de todos os fatores pesquisados, entre as quais se destacam: implantar um sistema informatizado para o agendamento do transporte, investir na capacitação e profissionalização da secretaria e dos motoristas, melhorar a disponibilidade de motoristas e veículos da instituição, melhorar as condições mecânicas dos veículos e realizar pesquisas de satisfação/avaliação das viagens após o término de cada uma.

Como contribuições deste estudo para a administração pública, ressalta-se a identificação das práticas que vêm sendo realizadas pelo setor e das melhorias possíveis, que podem subsidiar a gestão para a tomada de decisões, possibilitando uma revisão dos seus instrumentos e processos, com vistas a corrigir deficiências e aperfeiçoar o serviço. Para a academia, as principais contribuições referem-se à ampliação do conhecimento, como forma de contribuir para o avanço de estudos na área de qualidade dos serviços e, especialmente, do serviço público.

Como limitações deste trabalho, destaca-se que este abarcou apenas o setor de transporte do campus de Santa Maria, não considerando o transporte dos outros campi. Nesse sentido, recomenda-se tal prática para futuras pesquisas. Ademais, para trabalhos futuros, sugere-se a replicação da metodologia adotada neste estudo para avaliações em outros setores da UFSM, bem como em outras organizações públicas, com o propósito de melhorar a qualidade dos serviços prestados por estas, as quais possuem uma responsabilidade direta com a sociedade e devem prezar pela eficiência e eficácia.

\section{Referências}

Almeida ATC et al. (2018). Análise da eficiência dos departamentos de economia de instituições de ensino superior do brasil. Economia aplicada, 22(1), 109-40. 
Antunes EM \& Simões FA. (2013). Engenharia urbana aplicada: um estudo sobre a qualidade do transporte público em cidades médias. Revista Brasileira de Gestão Urbana, 5(2): 51-62.

Antunes MG et al. (2017). Avaliação da qualidade do serviço de transporte público de ônibus na cidade de Santos. Revista FATEC Zona Sul, 3(2): 18-39.

Bakti IGMY \& Sumaedi S. (2015). Quality paper P-TRANSQUAL: a service quality model of public land transport services. International Journal of Quality \& Reliability Management, v. 32(6), 534-558.

Bartnik FMP \& Silva IM. (2009). Avaliação da ação extensionista em universidades católicas e comunitárias. Avaliação, 14(2), 453-69.

Brasil. (2017). Decreto n. 9.094, de 17 de julho de 2017. Dispõe sobre a simplificação do atendimento prestado aos usuários dos serviços públicos, ratifica a dispensa do reconhecimento de firma e da autenticação em documentos produzidos no País e institui a Carta de Serviços ao Usuário. Diário Oficial da União, Poder Executivo, Brasília, DF.

Brasil. (1995). Lei n. 8.987, de 13 de fevereiro de 1995. Dispõe sobre o regime de concessão e permissão da prestação de serviços públicos previstos no art. 175 da Constituição Federal, e dá outras providências. Diário Oficial da União, Poder Executivo, Brasília, DF.

Brasil. (1997). Ministério da Administração Federal e Reforma do Estado. Programa da qualidade e participação na administração pública. Brasília: Mare.

Brasil. (2009). Ministério do Planejamento, Orçamento e Gestão. Programa Nacional de Gestão Pública e Desburocratização - GESPÚBLICA. (2009). Documento de Referência; Fórum Nacional 2008/2009. Brasília.

Brasil. (2014). Gestão Pública e Desburocratização - GESPÚBLICA. (2014). Ministério do Planejamento, Orçamento e Gestão. Secretaria de Gestão Pública. Programa GESPÚBLICA Carta de Serviços ao Cidadão: guia metodológico. Brasília. 
Carvalho MSMV \& Tonet HC. (1994). Qualidade na administração pública. Revista de Administração Pública, 28(2), 137-52.

Carvalho HA. et al. (2018). Avaliação institucional em uma universidade pública brasileira multicâmpus: processos e desafios na qualificação da gestão. Avaliação, 23(1), 217-43.

Castro Jr. DFL et al. (2013). Qualidade de serviço: um estudo bibliométrico nas bases de dados internacionais. Revista de Ciências da Administração, 15(36), 49-68.

Costa PHS et al. (2017). Avaliação da qualidade nos serviços de transporte rodoviário interestadual semiurbano de passageiros da região do Distrito Federal e dos municípios de seu entorno. Transportes, 25(4), 83-95.

Cronin J \& Taylor S. (1992). Measuring service quality: A reexamination and extension. Journal of Marketing, 56(3), 55-68.

Cunha LM et al. (2017). Gestão da qualidade nas organizações públicas: aplicação do SFMEA como ferramenta de melhoria administrativa em uma instituição federal de ensino superior. Espacios, 38(6), 13-21.

Donato $\mathrm{M}$ et al. (2017). Metodologia para verificar a qualidade da avaliação quanto à percepção dos usuários sobre o transporte público rodoviário da cidade do Rio de Janeiro. Negócios em Projeção, 8(1), 199-210.

Fitzsimmons JA \& Fitzsimmons MJ. (2005). Administração de serviços: operações, estratégia e tecnologia da informação. Porto Alegre: Bookman.

Freitas ALP \& Reis TB. (2013). Avaliação do transporte público urbano realizado por ônibus: uma abordagem exploratória. Revista Produção Online, 13(3), 814-842.

Grohmann MZ et al. (2014). Avaliação dos serviços de transporte aéreo brasileiro: análise da imagem e da atitude como antecedentes da intenção de uso. Gestão \& Produção, 21(1), 21527. 
Hair JF et al. (2009). Análise multivariada de dados. 6.ed. P.Alegre: Bookman.

Kotler P \& Keller KL. (2006). Administração de marketing. 12.ed. São Paulo: Pearson Prentice Hall.

Lima KR et al. (2015). A avaliação da qualidade de um sistema de metrô. Revista Inteligência Competitiva, São Paulo, 5(3), 14-34.

Lovelock C \& Wright L. (2001). Serviços: marketing e gestão. São Paulo: Saraiva.

Lübeck RM et al. (2011). Qualidade no transporte coletivo urbano. FACEF Pesquisa, 14(3), 264-77.

Mattos VLD et al. (2017). Um instrumento para medir a satisfação dos passageiros de um sistema de transporte público. GEPROS. Gestão da Produção, Operações e Sistemas, 12(1), 63-81.

Miguel PAC \& Salomi GE. (2004). Uma revisão dos modelos para medição da qualidade em serviços. Revista Produção, 14(1), 12-30.

Moreira Jr FJ et al. (2015). Satisfação dos usuários do restaurante universitário da Universidade Federal de Santa Maria: uma análise descritiva. Sociais e Humanas, 28(2), 83108.

Ojo TK et al. (2015). Students' satisfaction of campus shuttling bus services: a qualbus approach. Management Research and Practice, 7(1), 68-79.

Parasuraman A, Zeithaml VA \& Berry LL. (1988). Servqual: a multiple item scale for measuring consumer perceptions of service quality. Journal of Retailing, 64(1), 12-40.

Pereira, V. R. et al. (2013). Um estudo bibliométrico sobre a evolução da pesquisa da qualidade em serviço. Revista Produção, 23(2), 312-328.

Pérez MS et al. (2007). Effects of service quality dimensions on behavioural purchase intentions: a study in public-sector transport. Managing Service Quality, 17(2), 134-51. 
Ramos MP \& Schabbach LM. (2012). O estado da arte da avaliação de políticas públicas: conceituação e exemplos de avaliação no Brasil. Revista de Administração Pública, Rio de Janeiro, 46(5), 1.271-94.

Santos SM (2015). O desempenho das universidades brasileiras nos rankings internacionais: áreas de destaque da produção científica brasileira. 344 p. Tese (Doutorado em Cultura e Informação) - Universidade de São Paulo, São Paulo, SP.

Soares JR et al. (2019). Indicadores de gestão e de qualidade nas instituições federais de ensino superior brasileiras - 2009 - 2016. Revista Eletrônica de Administração, 25(2), 215 39.

Universidade Federal de Santa Maria - UFSM. (2011). Regimento Geral da Universidade Federal de Santa Maria. Acesso em 27 jan. 2020, em http://w3.ufsm.br/cefd/images/regimento_geral.pdf

Universidade Federal de Santa Maria - UFSM. (2019). UFSM em números. Acesso em 20 fev. 2019, em https://portal.ufsm.br/ufsm-em-numeros/publico/index.html

Vila N \& Gimeno-Martínez C. (2010). Efectos de la RSC sobre el consumidor: una aplicación al sector de transporte público terrestre. Innovar, 20(38), 235-55.

\section{Porcentagem de contribuição de cada autor no manuscrito}

Laís Viera Trevisan - 60\%

Daniel Arruda Coronel - 40\% 